Article

\title{
The Impact of Brexit on the Stock Markets of the Greater China Region
}

\author{
Lucía Morales $1, *$ (i) and Bernadette Andreosso-O'Callaghan ${ }^{2,3}$ \\ 1 Department of Accounting and Finance, Dublin Institute of Technology, Dublin D02, Ireland \\ 2 Jean Monnet Chair of Economics, Kemmy Business School, University of Limerick, Limerick V94 T9PX, \\ Ireland; bernadette.andreosso@ul.ie \\ 3 IRL and International Research Fellow, Ruhr University Bochum, 44801 Bochum, Germany \\ * Correspondence: lucia.morales@dit.ie; Tel.: +353-1-402-3230
}

Received: 31 January 2018; Accepted: 7 May 2018; Published: 10 May 2018

\begin{abstract}
An examination of Brexit and its initial impact on the main stock markets in the Greater China Region (GCR) was conducted using augmented market models that integrate Economic Policy Uncertainty (EPU) and implied volatility (VIX). The results do not seem to align with research in the field that has suggested that the EPU index helps to identify if market participants are reacting to political events. The main research findings suggest that Brexit does not appear to have an impact on the performance of market returns in the region and the influence of economic policy uncertainty in the GCR appears to be insignificant, except for Hong Kong. Overall, China's stock markets do not seem to be panicking and overreacting to unfolding events in the UK, and market instability in the region appears to be more associated with global and regional events that are better captured by the VIX index.
\end{abstract}

Keywords: Brexit; rising China; globalisation; stock markets; Economic Policy Uncertainty; political turbulences

JEL Classification: F36; F65; G15

\section{Introduction}

The year 2016 is described by Chen et al. (2017) as the year of global black swan events. Britain voted to leave the European Union, Donald Trump was elected as the US president, and a general sentiment towards protectionism, inward-looking economies, and immigration resistance seemed to be sweeping across several developed economies. Britain conducted public voting regarding breaking away from the EU on June 23, ending with approval as 52 percent of voters chose to leave the EU. The referendum outcome led to a significant upsurge of market uncertainty in the European and global financial markets that materialized by the decline of several stock market indices over a short period of time. More specifically, in the EU as a whole, the outcome of the Brexit referendum outcome has led both the UK and the EU-27 to reconsider their economic relationship with the outside world, and in particular with the Greater China region (GCR). China is the second main trading partner of the EU as a whole - after the USA — and within the EU-28, the UK is China's second largest trading partner-after Germany - with Sino-UK trade in goods reaching $\$ 78.54$ billion, or 14 percent of trade among all the 28 EU members in 2017, as reported by the General Administration of Customs of the People's Republic of China. Moreover, China is the largest investment source in the UK, with Chinese direct investment inflows doubling in 2017 compared with the previous year, according to figures released by the Rhodium Group. The UK has a negative trade balance with China, although it has a surplus in the area of services (UK Trade, August 2013-Statistical Bulletin). On the financial side, the relationship 
can be considered as underdeveloped, as China exercises strong control over foreign investment and its international capitals outflows. Moreover, the relationship between China and the UK is grounded in history, with for example the first Chinese community in Europe establishing itself in Liverpool. Given the relative importance of the UK economy to the EU economic connection with China, the withdrawal of the UK from the EU framework is bound to have an impact on a privileged economic partner such as China, as suggested by old and new trade theories. In the area of finance, how the GCR stock markets reacted to the Brexit referendum outcome is a relevant research objective. The stock markets in the GCR have developed independently with idiosyncratic institutional features alongside the development of cross-market linkages, as observed by the increasing number of Mainland companies listed on the Hong Kong stock exchange and by the closer economic ties between the two regions (Ho and Zhang 2012). Therefore, the main hypothesis explored in this study is to understand whether the UK's decision to leave the EU has generated significant disruptions in the stock markets of the GCR, since stock markets are considered to be a barometer mirroring how early signs of global economic and financial distress can spillover towards the real economy. An extant body of knowledge brings evidence of how stock markets are able to react and show signs of economic distress at early stages with potential ramifications for the real economy. The present study is even more welcome given that the degree of integration among stock markets around the globe has increased significantly over the past two decades, and that emerging economies are being affected by government policies that seek to liberalize their markets. Rapid technological progress and financial innovation have contributed to the development of significant economic integration between advanced and emerging financial markets (Palamalai et al. 2013), further justifying the need to study whether Brexit uncertainty could spillover to the GCR. New evidence that explores how market interdependencies are evolving in the case of a shock such as Brexit is therefore needed.

This study is supported by three market models that seek to find out whether indices such as the Economic Policy Uncertainty (EPU) and implied volatility (VIX) can help identify market dynamics in the region and whether market instability generated by the Brexit referendum outcome managed to shake up the behavior of the main stock markets in the region. More specifically, this paper seeks to offer evidence on how Brexit political uncertainty in the UK could have potential spillover effects on China's main stock markets. The reason for widening the analysis to the GCR stems from the fact that Mainland China stock markets share significant linkages with the Hong Kong and Taiwan stock exchange markets and as such, these market dynamics could offer valuable information to investors and policy makers regarding the expected reactions in the region. The central research question, whether the UK political instability has spilled-over to Chinese stock markets, is addressed by offering some insights into the literature that examines economic and political uncertainty and their implications for stock markets (Section 2). Section three outlines the background on Brexit, to help better understand what kind of challenges China faces when looking at its new relationship with the UK and the EU. Section four discusses the research sample and outlines the paper's methodological framework. Section five deals with the main findings and their analysis while section six concludes the study.

\section{Economic and Political Uncertainty Effects on Stock Markets}

Research connecting political uncertainty with stock market volatility suggests that a significant loss of wealth can be materialized due to the unstable political systems of a country (Root 1973; Brewer 1981; Simon 1982; Clark 1997; Clark and Tunaru 2003). Thus, monitoring stock market behavior can help identify if political events end up generating spillover effects to the real economy, and as such financial market uncertainty can be used to understand if political events generate wealth damage in a country. The recent literature looking at economic policy uncertainty and stock markets include Arouri et al. (2016) with their analysis of the US stock markets over the period 1900-2014; they find that an increase in economic policy uncertainty (EPU) reduces, in a significant manner, stock returns with the effect being stronger during extreme volatility periods. Scholars have also 
studied the implications of policy shocks on macroeconomic variables such as growth, inflation, and employment (Fernández-Villaverde et al. 2014) with some limitations regarding studies that integrate stock markets (Antonakakis et al. 2013; Brogaard and Detzel 2014; Kang and Ratti 2013, 2015; Liu and Zhang 2015). The understanding of the implications derived from policy uncertainty on the real economy is significant as economic agents take decisions based on the political climate and as such, employment, investment, consumption, and saving decisions are all affected (Gulen and Ion 2013). In terms of financial markets, economic and political uncertainty can foster an increase of financial risk that can lead to a negative impact on variables such as inflation rates, interest rates, market risk premia, stock market behavior, and international oil market performance (Pastor and Veronesi 2012, 2013; Chang et al. 2015). Given the limited literature studying the impact of economic and political uncertainty on the performance of stock markets in the background of Brexit, this study seeks to contribute to the field by examining if Brexit has generated significant distortions in the stock markets of the Greater China Region. As such, there is a need for a better understanding of the connections that exist between China and the UK and in which way their financial systems might be interconnected in the context of increasing interdependencies among the world's financial markets due to the processes of globalization that have taken place over the past three decades.

\section{Background on Brexit and Implications for China}

The UK is the third largest economy in the EU, and its departure from the European Union is associated with political and economic concerns. Although Brexit brings challenges, it also brings new opportunities, as by leaving the EU, the UK will need to engage in the development of new economic linkages with the rest of the world that replace the economic gains enjoyed by being a member of the EU. The UK has enjoyed a privileged position as a member state by maintaining full involvement in the decision-making process during its 43 years of EU membership, while benefitting from significant opt-out and opt-in clauses, making it perhaps quite difficult to understand its decision of giving up the benefits and advantages associated with such an advantageous position (Leinen 2016; Wang 2017). The Brexit outcome and its derived consequences may be closely linked to the inability of political leaders to make difficult and needed decisions and to develop policies that look after citizens' interests and demands. Luo (2017) argues that the outcome from the UK referendum reveals clear divisions between socio-economic classes that cohabit in the EU. Recent voting patterns offer disturbing evidence of economic inequality that has been aggravated by the Euro crisis. Income inequality has been rising markedly and this has been identified as a serious symptom of wrong or bad governance. Moreover, unemployment rates remain seriously high among many European countries and the stagnation of the middle-income class contributes to increasing discontent among voters. A general look at the British referendum and at the history of the EU project shows that European integration has failed to account for social integration and for citizens' protection, since the model is mainly supported by two core pillars: (i) the creation of a single market; and (ii) a joint currency. The pillars that cover monetary aspects have tended to marginalize the social dimension of the project and have created serious fractures among and within EU member states. The mood in Europe is nurtured by income inequality, by remote and non-accountable unelected bureaucrats, by big corporations that are perceived to subordinate the political class, all ending up with the undermining of basic precepts of the democratic system as a whole. The global financial crisis created a sentiment of deep discontent, with political leaders deciding to bail out big banks and financial institutions at the expense of the taxpayer. Those same banks that were at the very center of the global financial crisis caused a sentiment of deep frustration and grievance among the lower income groups in particular.

\subsection{China's Aspirations in Terms of a Market Economy}

An initial drawback to China's ambitions to gain market economy status (MES) has been jeopardized by Brexit, as Beijing considered the UK as one of its strongest advocates in that matter (European Parliament 2016). Full market access to the EU is of vital importance to China 
to enable sustained growth as it would help China deal with its excessive industrial capacity (People's Daily 2016). But at the same time, British interests are also impacted, as Chinese investors' plans to reach 500 million European consumers through the UK may be lost (Yu 2016a, 2016b). Chinese investors need to develop skills that help them understand and manage both the political risks and the uncertainty related to dramatic shifts in mature democratic economies, as they prepare to engage with mature and developed free market economies, if they wish to become leading players in global economic activities. This task is uneasy as links with Beijing are perceived with suspicion and with some level of hostility, with Chinese State-Owned Enterprises (SOEs) being quite often affected by a lack of transparent corporate governance frameworks and by some difficulties in explaining clearly their investment purposes. Furthermore, due to their strong ties with the government, doubts arise regarding the purpose of overseas investment plans that could be understood as being politically directed rather than being assessed on their commercial worth. In May 2016, the European Parliament rejected granting MES status to China (Hufbauer and Cimino-Isaacs 2016), as the EU voiced concerns regarding China taking advantage of economic competition within Europe. The fact that China has failed to secure market economy status is not surprising in a context where the world's most developed economies are struggling with a growing sentiment of protectionism. Since the mid-1990s, China's economy has shown a sustained high level of growth with a low inflation rate that is striking when compared to neighboring countries frequently impacted by financial and economic instability and by the doldrums of the world economy (Pan 2015). China has been able to maintain rapid export growth, while enduring unfair trade environment pressures such as the non-recognition of market economy status by both the EU and the USA (Mahbubani 2017). Therefore, in the current context where protectionism is on the rise, China's aspirations to become a market economy might linger over the next few years.

\subsection{Is Brexit a Real Concern for China?}

China is the world's most populous country (Henderson and Pils 2016), with historical connections to the UK locatable in the dark era of colonialism. The political wave that led to the success of the Brexit referendum is remarkably based on an antiforeigner sentiment that might have significant repercussions regarding the UK's future relationships with China, since potential restrictions could be imposed on foreign ownership and on real property in the UK that would have an impact on Chinese politico-economic elites with interests and investments in the country (Le Corre and Pollack 2017). The impact of Brexit on London as a financial center can lead to a reduction of London's international representation that could materialize in the reduction of the sales of services with repercussions on its trading relationship with China. Chinese citizens travel significantly to the UK on a yearly basis: these include tourists, students, business professionals, government representatives, and asylum seekers. Although the UK government has introduced changes regarding immigration with the aim of introducing restrictions to people that wish to enter the UK border. In the case of China, the UK has implemented policies that are making the UK entry more accessible for Chinese citizens (excluding Hong Kong Chinese citizens, who are subject to different rules). Previously, the process was quite bureaucratic, and as such, new arrangements have contributed to making visitor Visas more easily available, confirming the UK government's effort to make the UK a more attractive destination for citizens of the People's Republic of China. Currently, the UK's trade relationship with China is still conditioned by the UK's membership to the EU, which has been based on its "constructive engagement" approach vis-à-vis China. Initial reactions in China, in relation to the Brexit outcome, showed that the UK leaving its partnership with the EU would be perceived as a diminishing role played by the UK in world affairs. For the UK, its divorce from the EU means that its relationship with China is reduced to a state-to-state relationship, while for China a channel that could help influence EU decisions is lost. For the EU, the UK's withdrawal means losing a relevant player in the context of human rights and rule of law initiatives. There is little expectation that Brexit might create major problems for China, while the UK case is more delicate, as it might commit to a country that raises global concerns regarding its legal 
and political system and as a result the UK could become potentially isolated from global economic and financial affairs. According to Yu (2017) Brexit brings major challenges and political uncertainty, but it also brings interesting opportunities to the Chinese economy and in particular in relation to how it reconsiders its future relationship with the EU. This relationship is characterized by very complex foreign policies that will need to be re-examined. At the moment, China's position aligns with the views expressed by Japan and the US that share the opinion that the UK should remain part of the EU.

\section{Data and Methodological Approach}

\subsection{Data Description}

The research sample is based on stock market indices with a daily frequency and these were downloaded from Datastream, allowing us to study the performance of the GCR stock markets in the context of Brexit. To enable the study, the FTSE 100 index is used as a proxy for market behavior in the UK that will capture market dynamics in the country of origin suffering from political uncertainty. In the case of the GCR, the selected indices are: for Taiwan, the TSE Composite index, for Hong Kong, the Hang-Seng index, and for Mainland China, the Shanghai Security Exchange SSE composite and the Shenzhen Se Composite indices to measure stock market performance in the "Greater China Region". The sample covers the period June 2015 to December 2017, allowing the study of stock markets before and after the outcome of the Brexit referendum. To control for political instability, the EPU index for the UK (Baker et al. 2016) and the VIX Index are also included as part of the study. The UK EPU index is computed on the basis of daily news from newspaper archives that contain thousands of newspapers and other news sources from across the globe. Studies using EPU indices (Baker et al. 2012, 2014, 2016) suggest that the indices are a good proxy for real-word economy policy uncertainty (Wang et al. 2014). The OLS and the robust OLS regression estimation processes were considered to support the market models' estimations. The robust OLS estimation was added as part of the methodological framework, as it is well-known that OLS estimates are extremely sensitive to outliers that can have large effects on OLS estimates. Robust methods are less likely to be weakened by outliers, heteroscedasticity and non-normality issues, as robust methods help to minimize the violation of the OLS classical assumptions. Furthermore, robust regression allows for an improvement of the representativeness of the studied research sample, and this contributes to cross-checking the research findings for consistency. The OLS estimation is corrected by the Newey-West covariance coefficient. In the case of the OLS robust regression the M-estimation with the Huber type covariance estimation was used to ensure that the model outcomes do not suffer from serial correlation. This study seeks to contribute to the body of knowledge by offering an analysis that integrates economic policy uncertainty as a variable that helps to adjust proposed econometric models with the aim of creating a stronger filter for the political event under consideration. Additionally, the inclusion of the VIX index will help to measure market uncertainty and to cross check the different outcomes in a global context.

\subsection{Uncertainty Measures (VIX and EPU)}

The VIX is considered as an indicator of expected market volatility. The index is derived from option premia in the S\&P 500, and it is used as an indicator of what markets expect will happen. The VIX is computed on the basis of prices for near-term S\&P 500 options that measure market expectations of volatility over a rolling 30-day period. The VIX is established by millions of traders, engaging in millions of transactions. As such, when the VIX increases it means that there are more buyers than sellers in the marketplace, with the opposite happening in the case of a downward movement in the VIX. The weighted average of all the option prices in the S\&P 500 makes up what is known as the Volatility index. The VIX is an index of 30-day option implied volatility and it is considered by Baker et al. (2016) as the most obvious comparator to their EPU index. The authors show how the VIX has a correlation of 0.58 with the EPU index, and as such, while they move together there is also 
scope for variation, as the VIX showed strong reactions to events such as the Asian Financial Crisis, the WorldCom Fraud, and the Lehman Brothers collapse-all events that had a strong financial and stock market connection. On the other hand, the EPU index is found to react strongly to events associated with wars, with the election of a new president and with political battles that also generate stock market volatility. The EPU index captures and quantifies newspaper coverage of economic policy uncertainty between forecasters (Reboredo and Uddin 2016). Baker et al. (2016) developed an index to deal with economic policy uncertainty (EPU) that is based on newspaper coverage frequency and that proxies for movements in policy-related economic uncertainty. They find that stock markets react to shocks and that at the macroeconomic level, policy uncertainty leads to a decline in investment, output, and employment in the context of the US and twelve major economies. As such, the EPU index appears to be a better option in the context outlined in this paper, but as a way of cross checking the results, and measuring the level of openness and maturity of the GCR stock markets, the VIX is introduced as it can add interesting insights into the discussions. Furthermore, as the research study is looking into uncertainty generated in the financial system, and in particular in the Chinese stock markets, it is considered appropriate to include the VIX as a proxy for global market uncertainty. Therefore, when economic uncertainty is rising, it is expected that the VIX index will follow suit. However, this kind of trend has not been observed recently in market behaviors, and divergences between the two indices are found. Financial markets are complicated systems, where stability is affected by the occurrence of events such as crises, shocks and "black swans" that lead to instability that can spillover to the real economy. As such, the inclusion of the EPU index in the context of this study is well supported by existing evidence that indicates that economic policy uncertainty impacts in a significant manner several variables that affect the real economy. Therefore, governments need to be aware of it, as it helps to identify patterns of concern among stock markets, as they can generate serious distortions that can spillover to the real economy. Baker et al. $(2014,2016)$ developed a specific index that considers the case of the UK, and this index supports this study as it helps to analyze if the decision of the UK to leave the EU is having any initial impact on stock market behaviors in the Greater China Region (GCR). It is important to consider that as countries are impacted upon by international and domestic developments, uncertainty is derived from such events and countries can be subject to different levels of market volatility. Consequently, it is important to consider that the VIX reacts strongly to events that are associated with strong financial and stock market connections, while the EPU index evaluates responses to political issues such as wars, presidential elections, political battles based on fiscal policies, and events that are related to major policy concerns that can spillover to stock markets (Baker et al. 2016). The researchers expect the two indicators to be reflected in the behavior of the GCR stock markets that are characterized by limited financial connections between China and the UK.

The line of research followed in this paper is in line with the insights of Pastor and Veronesi (2012, 2013), who model the links among fluctuations between policy uncertainty and stock market volatility. The difference in this study is that it seeks to understand the reactions on market returns derived from policy uncertainty over a relative short time period. To sum up, the variables considered as part of this research study include: (i) the EPU index for the UK developed by Baker et al. $(2012,2014,2016)$ that has been used in a variety of research papers mainly focused on the economic context because the EPU index is considered a good indicator of economic risk; (ii) The VIX is also included to measure market risk in a global context; (iii) The main stock indices for the GCR are considered to help measure market instability after the British referendum on continued EU membership; (iv) The FTSE 100 is the proxy for systematic risk; and (v) the UK 3-month Treasury Bill is the risk-free rate.

\subsection{Empirical Models}

Three market models were considered to help understand market dynamics over the chosen sample period. The models were chosen after careful consideration of the existing literature modelling political uncertainty and implications for stock market behaviors. Lean and Nguyen (2014); Goodell 
and Vähämaa (2013) and Bin et al. (2004) all offered valuable insights regarding the need for estimating different models that help cross check research outcomes in the context of a limited number of observations that do not allow for the implementation of more sophisticated econometric modelling. Furthermore, in the case of Lean and Nguyen (2014), the authors used an augmented model that included market performance and economic policy uncertainty, where a dynamic term was introduced to capture the impact of EPU, an approach that was used as a guide on this paper. As a result, the econometric modelling followed in this study and outlined below is supported by three research models that would help cross-checking if the research outcomes are consistent over the period of study.

Model 1

The first market model is defined after markets start to show signs of recovery to avoid noise generated from the lingering effects of the GFC (Global Financial Crisis). The excess return market model with the dummy variable $\left(D_{1 t}\right)$ accounting for Brexit is considered.

$$
\left(R_{i t}-R_{f}\right)=\beta_{10}+\beta_{11}\left(R_{i t}-R_{f}\right)_{t-1}+\beta_{12}\left(R_{m t}-R_{f}\right)_{t-1}+\beta_{13} D_{1 t}+\varepsilon_{1 t}
$$

where $R_{i t}$ (are GCR returns), $R_{m t}$ (FTSE 100 returns), $R_{f}($ UK 3 month $T-$ bill $) . R_{i t}$ represents the returns for the index under consideration (for China: it is the Shanghai Se Composite and Shenzhen Se Composite Indices; for Hong Kong: Hang Seng Index, for Taiwan: Taiwan Se). With the aim of capturing the impact of policy and market uncertainty the model is augmented to consider the impact of the EPUi (model 2), and the VIX index (model 3). A dummy variable is introduced in the models to consider the outcome of the British referendum. The dummy variable takes a value of one from the 24 of June 2016 onwards, when British voters chose to leave the EU and zero otherwise. To account for the impact of the EPU index in the case of the UK, model 2 is considered, and the model is augmented by introducing the EPUi as an independent term. The behavior of the stock market in the GCR and the market index represented by the FTSE 100 are captured by the variables adjusted to the Brexit period that allow monitoring whether economic and political uncertainty generated by Brexit impacts upon stock market returns in the China region over the period under study. Model 3 is outlined to consider if the GCR is more sensitive to global market uncertainty that would be captured by the VIX index, and consequently, the model is augmented to capture market dynamics and the volatility index is used to account for instability after the Brexit outcome.

Model 2-Economic Policy Uncertainty Index (UK EPUi)

To account for the impact of UK economic policy uncertainty on the performance of the stock markets in the GCR, model one is augmented by adding the EPUi variable that would help identify if economic uncertainty in the UK does have a significant impact on the selected stock markets. Additionally, the dummy variable allows us to identify whether there are variations with regard to market risk sensitivity (captured by $\beta_{21}$ and $\beta_{212}$ ) over the Brexit period and to find out if economic policy uncertainty with origins in the UK has an impact on the performance of stock markets in the GCR ( $\beta_{23}$ and $\beta_{213}$ caputure such an impact $)$.

$$
\begin{aligned}
\left(R_{i t}-R_{f}\right)=\beta_{20} & +\beta_{21}\left(R_{i t}-R_{f}\right)_{t-1}+\beta_{22}\left(R_{m t}-R_{f}\right)_{t-1}+\beta_{23} \Delta \ln (E P U i) \\
& +D_{1 t}\left[\left(\beta_{210}+\beta_{211}\left(R_{i t}-R_{f}\right)_{t-1}+\beta_{212}\left(R_{m t}-R_{f}\right)_{t-1}\right.\right. \\
& \left.+\beta_{213} \Delta \ln (E P U i)\right]+\varepsilon_{2 t}
\end{aligned}
$$

Model 3-Implied Volatility Index (VIX)

Market model three follows the same logic as market model two, but in this case the Implied Volatility Index is considered to follow the arguments outlined by Baker et al. (2016) that consider VIX an adequate proxy to measure for economic and financial uncertainty, and to help capture changes 
in global market uncertainty and the implications for market performance in the GCR. In this case, market risk sensitivity is captured by $\beta_{31}$ and $\beta_{312}$. The impact of EPUi is captured by $\beta_{33}$ and $\beta_{313}$.

$$
\begin{aligned}
\left(R_{i t}-R_{f}\right)=\beta_{30} & +\beta_{31}\left(R_{i t}-R_{f}\right)_{t-1}+\beta_{32}\left(R_{m t}-R_{f}\right)_{t-1}+\beta_{33} \Delta \ln (V I X) \\
& +D_{1 t}\left[\left(\beta_{310}+\beta_{311}\left(R_{i t}-R_{f}\right)_{t-1}+\beta_{312}\left(R_{m t}-R_{f}\right)+\beta_{313} \Delta \ln (V I X)\right]\right. \\
& +\varepsilon_{3 t}
\end{aligned}
$$

To support the research framework and to align the study with common approaches followed by some researchers in the field, such as for example the study developed by Lean and Nguyen (2014), the integration of conditional volatility of financial returns was considered using Generalized Autoregressive Conditional Heteroscedasticity (GARCH)-type models that would help to look after important features of portfolio returns, such as for example, volatility clustering, asymmetric volatility, and leverage effects. Three GARCH models were considered and implemented: GARCH, T-GARCH. and the EGARCH, models with the aim of looking after volatility dynamics and market behavior post-Brexit that could also examine if the EPU and VIX index picked up rising levels of market uncertainty due to Brexit and whether the lack of progress and clarity regarding the negotiations between the UK and the EU led to sustained market confusion. The specific models implemented were the GARCH $(1,1)$, the T-GARCH $(1,1)$ and the EGARCH $(1,1)$. Unfortunately, the implemented models were not suitable, as they were not stable in variance and were characterized by explosive behavior and a lack of stability combined with a significant outcome of coefficients that were not significant. The outcomes do not make it possible to support this study with a GARCH approach in the context of the outlined augmented models and considered variables limiting the scope of a more sophisticated econometric modelling. There is also a need to consider that the number of observations was quite limited, making it a plausible cause of the GARCH models are not able to perform.

\section{Findings and Analysis}

The analysis started with the required testing and data adjustments that help identify the basic properties of the series and that ensure that the chosen econometric framework would lead towards sound and robust results. The first stages look to transform the data into natural logarithms-a common practice in the field-that ensure stability properties (stationarity), and to adjust the returns to the risk-free rate (the UK 3-month T-Bill). Afterwards, a vector autoregression (VAR) model was implemented to identify the appropriate number of lags that were needed to ensure that the model was properly specified and to avoid creating unnecessary problems regarding model specification due to the selection of an inappropriate number of lags. The Schwarz and Hannan-Quinn Information Criteria were used to identify the appropriate number of lags as they are considered the best criteria when the research sample has more than 120 observations. Since both criteria offered consistent estimations, they were deemed as optimal options for the estimation of the lag length with an outcome of 1 lag to be used. The Bai Perron test was conducted to help identify the time period that would better align with the outcome of the British referendum and with the objective of minimizing as much as possible the interference of other shocks that will impact upon the clarity of outcomes. The results of the Bai Perron test ${ }^{1}$ showed that the series was affected by structural breaks since the hit of the Global Financial Crisis, with the latest break detected around the 10th of March 2015. These outcomes are supported by the graphical analysis conducted on the data since January 2005 until December 2017 that shows significant market fluctuations with at least three to five different breaks affecting the series. Consequently, after analyzing the charts and the outcomes of the multiple structural breakpoint test,

1 The results for the augmented Dickey-Fuller (ADF) test, vector autoregression (VAR) model for lag selection and Bai-Perron for structural breaks are not reported for the sake of brevity but are available upon request. 
it was deemed appropriate to examine the impact of Brexit on the series since June 2015 until the end of 2017, leaving the research sample down to 675 observations that were used to examine if Brexit generated an impact on the main stock markets in the Greater China Region (see research sample details in Table 1 below).

Table 1. Research Sample June 2015 to December 2017.

\begin{tabular}{ccccc}
\hline GCR Indices & UK Index & $\begin{array}{c}\text { British } \\
\text { Referendum }\end{array}$ & Risk Free Rate & Uncertainty Indices \\
\hline $\begin{array}{c}\text { Shanghai Se Composite } \\
\text { (Mainland China) }\end{array}$ & FTSE 100 & $\begin{array}{c}\text { 24th June 2016 to } \\
\text { December 2017* }\end{array}$ & UK T-Bill (3 month) \\
\cline { 1 - 2 } $\begin{array}{c}\text { Shenzhen Se Composite } \\
\text { (Mainland China) }\end{array}$ & CBIX)
\end{tabular}

\subsection{Preliminary Data Analysis}

The examination of the created charts covering the period of January 2005 to December 2017 (Figure A1 in the Appendix A) offer a pairwise breakdown between the FTSE 100 and the individual indices under study, showing that Taiwan and the Hang Seng patterns are closely aligned with the behavior of the FTSE 100, while the Shanghai and Shenzhen indices show some level of independent behavior when compared with the FTSE 100. The initial outcomes are confirmed by the charts comparing how the markets evolved after the Brexit results (Figure A2 in the Appendix A), indicating that the TSE Se index and the Hang Seng index appear to be linked to the patterns shown by the FTSE 100, while the Shanghai Se Composite and the Shenzhen Se Composite indices show a more independent behavior. The correlation matrix (see Table 2 below) for the post Brexit period also indicates that the connection between the FTSE 100 and TSE Se and the Hang Seng is positive with correlations that range from 0.46 to 0.40 , while in the case of Shanghai and Shenzhen, correlations remain positive, but with coefficients that are quite low, ranging from 0.16 to 0.15 , in line with the patterns identified in the chart analysis suggesting again more independent behavior in these markets. Another interesting result is how the markets are negatively connected with the proxies for market uncertainty, with the VIX and FTSE 100 showing a correlation of -0.49 , while the rest of the indices exhibited correlations that were quite close to zero in the case of the EPU, and between -0.24 and -0.16 in relation to the VIX. These results signal an inverse relationship with some markets and a lack of connection with other markets. The outcomes are quite interesting, as according to Baker et al. (2016) market correlations with the EPU index appear to be positive and higher, and correlations between the EPU and the VIX index are expected to be positive and quite high showing that both indices could be used as good proxies to measure political uncertainty.

Table 2. Correlation Matrix.

\begin{tabular}{cccccccc}
\hline Correlations & EPU & VIX & FTSE 100 & Hang Seng & Shanghai & Shenzhen & Taiwan \\
\hline EPU & 1.00 & 0.10 & -0.07 & -0.06 & -0.02 & -0.03 & -0.04 \\
VIX & 0.10 & 1.00 & -0.49 & -0.24 & -0.17 & -0.16 & -0.23 \\
FTSE 100 & & & 1.00 & 0.46 & 0.16 & 0.15 & 0.40 \\
Hang Seng & & & & 1.00 & 0.49 & 0.43 & 0.61 \\
Shanghai & & & & & 1.00 & 0.90 & 0.28 \\
Shenzhen & & & & & & 1.00 & 0.26 \\
Taiwan & & & & & & 1.00 \\
\hline
\end{tabular}


The outcomes from the main descriptive statistics (see Table 3 below) show that over the period the FTSE 100, the Hang Seng and the Taiwan Se average returns were positive and quite similar, while in the case of the Shanghai and Shenzhen Se Composite indices, the average returns were negative over the period. Each series under consideration exhibit negative skewness and excess of kurtosis, indicating that the probability distributions are skewed to the left and have a leptokurtic shape that indicates that the series are showing fatter tails than those that are normally associated with normal distributions. The Jarque-Bera test confirms the non-normality of the series, which is considered a common outcome when analyzing the basic properties of financial data. In terms of standard deviations, the five indices showed similar results with a slightly high outcome for the Shanghai and Shenzhen SE Composite indices. The charts looking at historical volatility (Figure A3 in the Appendix A) showed that the Brexit outcome did not bring major disruptions to the region, as volatility charts showed that the year 2015 and the first two quarters of the year 2016 were more volatile, with relatively stable behavior post-Brexit; a behavior that remained until the end of the year 2017. As such, the preliminary analysis shows a lack of significant evidence indicating that the main stock markets in the GCR were significantly disrupted by the British referendum outcome. The initial findings point to the limited relationship existing between the regions regarding their financial systems and also to the strong controls imposed by the Chinese authorities in their stock markets that impact upon their exposure to global events by keeping the country's stock markets relatively isolated.

Table 3. Descriptive Statistics.

\begin{tabular}{cccccc}
\hline Daily Returns & FTSE 100 & Hang Seng & Shanghai & Shenzhen & Taiwan \\
\hline Mean & 0.000143 & 0.000144 & -0.00046 & -0.00055 & 0.000132 \\
Std. Dev. & 0.01 & 0.01 & 0.02 & 0.02 & 0.01 \\
Skewness & -0.15 & -0.48 & -1.49 & -1.15 & -0.52 \\
Kurtosis & 5.86 & 6.36 & 11.22 & 7.31 & 7.14 \\
Jarque-Bera & 231.86 & 341.61 & 2142.47 & 670.65 & 510.21 \\
Observations & 673 & 673 & 673 & 673 & 673 \\
\hline
\end{tabular}

\subsection{Market Models Analysis}

The estimated beta coefficients look at the sensitivity of the GCR market returns to the market-wide source of risk (systematic risk measured by the FTSE 100), and their variation during the period of study. The analysis of market returns and how they were affected once the model is augmented to take into consideration market ambiguities due to political uncertainty that is captured by the EPU index and market distress captured by the VIX index, are also considered as part of the study. The outcomes from model one (see Table 4 below) show that the Asian markets are exhibiting a conservative behavior when compared with the FTSE 100 with positive beta coefficients: below one and quite low (ranging from 0.41 to 0.23 ). This shows that the markets are generating positive returns, with the post-Brexit period having a positive impact on market behavior in the case of the Hang Seng index, whereas no significant impact was found for Shanghai, Shenzhen and for Taiwan.

The augmented market model two (see Table 5 below), adjusted to consider the impact of political uncertainty on market returns, showed that the unfolding situation in the UK is associated with a slight general increase in materialized returns over the period under study when compared to those exhibited by model one, except for Taiwan where returns decreased slightly. The post-Brexit period was characterized by a negative impact on returns for the Hang Seng, Shanghai, and Shenzhen, with insignificant impact measured for Taiwan, which reported an insignificant coefficient. The EPU index does not seem to generate a negative impact on returns over the period, with significant positive coefficients in the case of Hang Seng market returns, and insignificant coefficients registered in the case of Shanghai, Shenzhen, and Taiwan. The results for the whole period align with the results reported by the first market model, indicating that the post-Brexit period is not associated with a negative impact on market returns. This suggests that economic uncertainty generated in the UK has 
not had a significant impact on market returns in the GCR, an outcome that could be explained by slow progress regarding the UK negotiations with the EU regarding specific implications of the UK leaving the European Union. In the case of the Hang Seng and Shenzhen indices, there was a positive effect on returns, while the Shanghai and Taiwan performance not being affected by instability in the UK with coefficients was found to be insignificant. Post-Brexit market returns are found to be significant and negative except for Taiwan, which had an insignificant outcome. The results indicated that the EPU index does not seem to be creating market uncertainty in the region and that the negative return performance during the post-Brexit period might be explained by more global and regional political events with limited impact from UK political uncertainty.

Table 4. Market Model 01.

\begin{tabular}{ccccc}
\hline Index & $\mathbf{f i}_{\mathbf{1 0}}$ & $\mathbf{f i}_{\mathbf{1 1}}$ & $\mathbf{f i}_{\mathbf{1 2}}$ & $\mathbf{f i}_{\mathbf{1 3}}$ \\
\hline \multirow{2}{*}{ Hang Seng } & $-0.00114^{* * *}$ & $-0.17217^{*}$ & $0.414099^{*}$ & $0.002088^{*}$ \\
& $(0.0641)$ & $(0.000)$ & $(0.000)$ & $(0.0098)$ \\
\hline \multirow{2}{*}{ Shanghai } & $-0.00174^{* * *}$ & 0.035676 & $0.270693^{*}$ & 0.001971 \\
& $(0.0627)$ & $(0.3522)$ & $(0.000)$ & $(0.1064)$ \\
\hline \multirow{2}{*}{ Shenzhen } & -0.00137 & $0.073093^{* * *}$ & $0.238844^{*}$ & 0.001261 \\
& $(0.2269)$ & $(0.0580)$ & $(0.000)$ & $(0.3961)$ \\
\hline \multirow{2}{*}{ Taiwan } & -0.00042 & $-0.07306^{* * *}$ & $0.232554^{*}$ & 0.000914 \\
& $(0.4769)$ & $(0.0741)$ & $(0.000)$ & $0.1367)$ \\
\hline
\end{tabular}

Levels of significance: ${ }^{*} 1$ percent and ${ }^{* *} 10$ percent. The estimated coefficients capture the following information: $\beta_{10}$ (the intercept); $\beta_{11}$ (excess returns for the GCR market under study); $\beta_{11}$ (excess market return); $D_{1 t}$ (dummy variable-post Brexit period). The Breusch-Godfrey LM test for serial fail to reject the null for no serial correlation, while the null for heteroskedastic residuals is rejected. The results for serial correlation and heteroskedasticity tests are reported in Table A1 in the Appendix A. The model estimation is then corrected by the Newey-West covariance coefficient variance and robust regression was also considered to check the model performance. Overall, the outcomes of the robust regression are consistent with the OLS estimators and for the sake of brevity they are not reported here. Market Model $01:\left(R_{i t}-R_{f}\right)=\beta_{10}+\beta_{11}\left(R_{i t}-R_{f}\right)_{t-1}+\beta_{12}\left(R_{m t}-R_{f}\right)_{t-1}+\beta_{13} D_{1 t}+\varepsilon_{1 t}$.

Table 5. Market Model 02.

\begin{tabular}{ccccccccc}
\hline Index & $\mathbf{f i}_{\mathbf{2 0}}$ & $\mathbf{f i}_{\mathbf{2 1}}$ & $\mathbf{f i}_{\mathbf{2 2}}$ & $\mathbf{f i}_{\mathbf{2 3}}$ & $\mathbf{f i}_{\mathbf{2 1 0}}$ & $\mathbf{f i}_{\mathbf{2 1 1}}$ & $\mathbf{f i}_{\mathbf{2 1 2}}$ & $\mathbf{f i}_{\mathbf{2 1 3}}$ \\
\hline \multirow{2}{*}{ Hang } & $-0.00111^{* * *}$ & $-0.2104^{*}$ & $0.480941^{*}$ & $-0.00327^{* *}$ & $0.002076^{* *}$ & 0.08463 & $-0.20593^{* *}$ & $0.003061^{* *}$ \\
Seng & $(0.0724)$ & $(0.000)$ & $(0.000)$ & $(0.0102)$ & $(0.0101)$ & $(0.3286)$ & $(0.0420)$ & $(0.0456)$ \\
\hline \multirow{2}{*}{ Shanghai } & $-0.00162 * * *$ & 0.034777 & $0.374193^{*}$ & -0.00258 & 0.00199 & -0.06959 & $-0.35048^{* *}$ & 0.003079 \\
& $(0.0833)$ & $(0.3854)$ & $(0.000)$ & $(0.1794)$ & $(0.1026)$ & $(0.6092)$ & $(0.0133)$ & $(0.1837)$ \\
\hline \multirow{2}{*}{ Shenzhen } & -0.00124 & $0.078269 * * *$ & $0.364629^{*}$ & $-0.00456^{* * *}$ & 0.001276 & -0.08247 & $-0.44308^{* *}$ & $0.005348^{* * *}$ \\
& $(0.2744)$ & $(0.0586)$ & $(0.000)$ & $(0.0515)$ & $(0.3893)$ & $(0.4620)$ & $(0.0100)$ & $(0.0581)$ \\
\hline \multirow{2}{*}{ Taiwan } & -0.00042 & -0.06704 & $0.226722^{*}$ & -0.00135 & 0.000928 & -0.02231 & 0.009932 & 0.001094 \\
& $(0.3704)$ & $(0.2035)$ & $(0.000)$ & $(0.1682)$ & $(0.1331)$ & $(0.7914)$ & $(0.8959)$ & $(0.3522)$ \\
\hline
\end{tabular}

Levels of significance: ${ }^{*} 1$ percent, $* * 5$ percent and ${ }^{* * *} 10$ percent. The model coefficients capture the following information: $\beta_{20}$ (intercept); $\beta_{21}$ (excess returns for the GCR market under study); $\beta_{22}$ (excess market returns); $\beta_{23}$ (impact of Economic Policy Uncertainty); $D_{1 t}$ (dummy variable—post Brexit period); $\beta_{210}$ (constant during the post-Brexit period); $\beta_{211}$ (excess returns for the GCR market under study post-Brexit); $\beta_{212}$ (excess market returns post-Brexit); $\beta_{213}$ (impact of economic Policy Uncertainty post-Brexit). The Breusch-Godfrey LM test for serial correlation failed to reject the null for no serial correlation. The White test rejects the null for homoscedastic residuals. The results for the Breusch-Godfrey LM and White test are reported in Table A1 in the Appendix A. The model estimation is then corrected by the Newey-West covariance coefficient variance and robust regression was also considered to check the model performance. Overall, the outcomes of the robust regression are consistent with the OLS estimators and, for the sake of brevity, are not reported here. Market Model 02: $\left(R_{i t}-R_{f}\right)=\beta_{20}+\beta_{21}\left(R_{i t}-R_{f}\right)_{t-1}+\beta_{22}\left(R_{m t}-R_{f}\right)_{t-1}+\beta_{23} \Delta \ln (\mathrm{EPUi})+$ $D_{1 t}\left[\left(\beta_{210}+\beta_{211}\left(R_{i t}-R_{f}\right)_{t-1}+\beta_{212}\left(R_{m t}-R_{f}\right)_{t-1}+\beta_{213} \Delta \ln (\mathrm{EPUi})\right]+\varepsilon_{2 t}\right.$.

The augmented market model three (see Table 6 below), that incorporates the VIX as an alternative measure for instability (financial markets uncertainty) confirms the results obtained from previous models that show that the selected Asian markets are exhibiting a conservative behavior with beta coefficients positive and lower than one, and with slight increases in returns when compared with the 
results reported by models one and two that highlight a better market performance over the period under consideration. The VIX highlights significant uncertainty over the period with all coefficients being significant and negative. This shows that the VIX is able to capture a more global impact on the Asian markets than the potential isolated effects that are documented in the case of the UK EPU index, which indicated that market instability seems to be perceived in a stronger manner in the UK's former colony than in the region with returns turning negative over the Brexit period. These returns cannot only be explained by the political situation in the UK as they appear to be more related to global and regional uncertainties affecting the markets over the period of study. The results show that the VIX appears to be a better proxy to capture market instability in the region, highlighting the limited connections in the financial context that exist between the UK and the GCR, with the exception of Hong Kong, which seems to be more sensitive to issues impacting the UK and in particular to its current political situation. Again, this result is not surprising given the historical ties existing between the UK and Hong Kong and considering that the Hong Kong stock market is considered mature and developed, while China and Taiwan's stock markets are considered emerging markets (Cheng and Glascock 2005).

Table 6. Market Model 03.

\begin{tabular}{|c|c|c|c|c|c|c|c|c|}
\hline Index & $\mathrm{fi}_{30}$ & $\mathrm{fi}_{31}$ & $\mathrm{fi}_{32}$ & $\mathrm{fi}_{33}$ & $\mathrm{fi}_{310}$ & $\mathrm{fi}_{311}$ & $\mathrm{fi}_{312}$ & $\mathrm{fi}_{313}$ \\
\hline Shenzhen & $\begin{array}{c}-0.00116 \\
(0.2958)\end{array}$ & $\begin{array}{c}0.076432 * * * \\
(0.0590)\end{array}$ & $\begin{array}{c}0.387264 \text { * } \\
(0.000)\end{array}$ & $\begin{array}{c}-0.07237 \text { * } \\
(0.000)\end{array}$ & $\begin{array}{c}0.001185 \\
(0.4127)\end{array}$ & $\begin{array}{l}-0.0818 \\
(0.4568)\end{array}$ & $\begin{array}{c}-0.46328 * \\
(0.0060)\end{array}$ & $\begin{array}{c}0.071946 \text { * } \\
(0.000)\end{array}$ \\
\hline Taiwan & $\begin{array}{c}-0.00032 \\
(0.4716)\end{array}$ & $\begin{array}{c}-0.10876^{* *} \\
(0.0290)\end{array}$ & $\begin{array}{c}0.252908 * \\
(0.000)\end{array}$ & $\begin{array}{c}-0.04694 * \\
(0.000)\end{array}$ & $\begin{array}{c}0.000823 \\
(0.1559)\end{array}$ & $\begin{array}{l}0.020725 \\
(0.7943)\end{array}$ & $\begin{array}{c}-0.01671 \\
(0.8155)\end{array}$ & $\begin{array}{c}0.046358 \text { * } \\
(0.000)\end{array}$ \\
\hline
\end{tabular}

Levels of significance: ${ }^{*} 1$ percent, ${ }^{* *} 5$ percent and ${ }^{* * *} 10$ percent. The model coefficients capture the following information: $\beta_{30}$ (intercept); $\beta_{31}$ (excess returns for the GCR market under study); $\beta_{32}$ (excess market returns); $\beta_{33}$ (impact of Economic Policy Uncertainty); $D_{1 t}$ (dummy variable-post Brexit period); $\beta_{310}$ (constant during the post-Brexit period); $\beta_{311}$ (excess returns for the GCR market under study post-Brexit); $\beta_{312}$ (excess market returns post-Brexit); $\beta_{313}$ (impact of economic Policy Uncertainty post-Brexit). The Breusch-Godfrey LM test for serial correlation rejects the null for no serial correlation. The White test rejects the null for homoscedastic residuals. The results for the Breusch-Godfrey and White test are reported in Table A1 in the Appendix A. The model estimation is then corrected by the Newey-West covariance coefficient variance and robust regression was also considered to check the model performance. Overall, the outcomes of the robust regression are consistent with the OLS estimators and are not reported. Market Model 03: $\left(R_{i t}-R_{f}\right)=\beta_{30}+\beta_{31}\left(R_{i t}-R_{f}\right)_{t-1}+\beta_{32}\left(R_{m t}-R_{f}\right)_{t-1}+\beta_{33} \Delta \ln (\mathrm{VIX})+$ $D_{1 t}\left[\left(\beta_{310}+\beta_{311}\left(R_{i t}-R_{f}\right)_{t-1}+\beta_{312}\left(R_{m t}-R_{f}\right)+\beta_{313} \Delta \ln (\mathrm{VIX})\right]+\varepsilon_{3 t}\right.$

Over the period, returns turn out to be negative, signifying that the market might be reacting to more global issues, such as political uncertainty originating in the USA (a major trading partner of China), with a lack of clarity regarding the country's international position since the arrival of Donald Trump to office. Political uncertainty in the region could be a result of political instability in neighboring countries, such as the political ambitions of the North Korean leader and the implications of the One Belt One Road (OBOR) initiative, which is not that welcome by countries such as Vietnam and Japan. The research outcomes seem to align partially with theoretical positions that indicate that policy uncertainty will lead to depressing market returns, with the findings showing evidence of market returns and policy uncertainty being negative, and with decreases in stock market returns as a response to unexpected policy uncertainty (Li and Peng 2017; Antonakakis et al. 2013; Brogaard and Detzel 2014; Kang and Ratti 2015; and Liu and Zhang 2015). The economic and financial justification of the outlined models' rests on the need of understanding if stock markets in the GCR can be used by investors when diversifying their portfolios during times of increased market uncertainty. As such, the region exhibits attractive features with regard to investment in the context of instability in the global economic environment, with China bound to play a major role, as major developed economies 
shift towards anti-globalization policies. The overall findings show that the GCR exhibits attractive features regarding its exposure to international shocks, as stock markets do not seem to have a strong reaction to them. On the other hand, the role of stock markets as a leading economic indicator is very limited in the region. Furthermore, domestic and regional instability must be considered carefully, as Chinese stock market performance has been significantly affected over the past few years.

\subsection{Has the UK Political Instability Spilled-Over to Chinese Stock Markets?}

Research studies that examine stock market reactions to political events and to market instability derived from such events are examples of a developing area of study. The paucity of research in the area is surprising in that a political environment that is viewed as stable and predictable is the basis of a county's ability to create a suitable environment that attracts investment (Benáček et al. 2014; Bin et al. 2004; Manzoor 2013). The Chinese stock market has suffered significant plunges since the outburst of the Global Financial Crisis and it has been kept afloat by massive state intervention. Corporate debt has increased, leaving China in a delicate economic situation. The findings by Chen et al. (2017) suggest that the outcome of the British referendum was received with significant levels of instability and market distress at the global level, with investors shifting from equity towards bond markets, except for the case of China. These research findings can be explained by the fact that China's financial system remains relatively closed and its lack of connection with international markets acted as a shield to global instability. As such, Brexit does not seem to have created major distortions in the Chinese financial markets, with the trade sector and currency markets being the ones that have been broadly exposed to global shocks. Again, these findings are not surprising as the openness of the stock market in Mainland China is still very limited, whereas Hong Kong's market is more integrated into the more developed markets. The stock markets in the GCR do not seem on the whole to share trends exhibited by developed economies in the long run, as stock markets in the region appear to be partially segmented, suggesting that the integration of Chinese stock markets with more mature markets can be characterized as weak and episodic (Guidi et al. 2016). Financial markets are very complex systems that are not secluded, and where globalization has contributed to remove isolation patterns market fluctuations can spread and spillover to other markets very quickly. The outcomes for the Hong Kong stock market are signaling that the market is affected by the disruptions to the UK's political context, which is also a market that is significantly exposed to global market uncertainty. As Hong Kong is considered a developed and mature economy, Chinese policy makers can derive interesting insight from this market reaction to global and regional effects when devising policies that seek to keep its financial system from opening, while monitoring and minimizing the kind of risks associated with the global and regional integration process. The Chinese authorities have implemented policies that seek to stimulate equity investment by foreign investors that are aimed at achieving a substantial degree of economic integration with many advanced countries while keeping tight controls over their own financial markets. As such, the GCR has managed to develop independently and with different idiosyncratic features; cross-market linkages and closer ties developed in this selected Asian Region present interesting insights for future investment as the region offers relative stability and diversification opportunities (Ho and Zhang 2012).

\section{Critical Insights and Conclusions}

The outcomes from this study show that the economic and political uncertainty originating in the UK only has a partial impact on the GCR. This impact appears to be limited to a negative impact on the Hong Kong stock market-the UK's former colony-while the other markets do not seem to be reacting to it. Furthermore, the VIX appears to be a better proxy to measure market uncertainty in the region and the post-Brexit period registered negative performance in returns except for Taiwan. The results do not confirm theoretical predictions and views indicating that policy uncertainty depresses stock returns (Lean and Nguyen 2014). Consequently, careful consideration is due regarding the level of development and financial integration of the (young) markets under study and their exposure to 
more global and regional events that might offer further insight in the area of markets dynamics. The research findings suggest that the Chinese stock markets might be more sensitive to global events, as outlined by the results from the augmented market model that integrated the VIX as a proxy for financial markets uncertainty, a result that indicates market instability in the GCR might be more related to global and regional events, with the British referendum outcome appearing to be quite limited in explaining the disruptions on the stock market of its former colony. Additionally, there is a need to consider that Brexit has not materialized yet with negative policies against China, but that, on the contrary, the UK is looking to strengthen and develop further connections with the rising Chinese economy. At the moment, these countries' relationship is mainly in the trade sector with strong limitations regarding financial interdependencies. An increasing connection between the UK and China is visible by the fact that Chinese foreign direct investment in 2017 has risen by far the highest amount in the UK compared with any other EU country during the same year. China's economic performance indicates that the country has managed to exhibit strong levels of growth over a relatively long period of time, even though discriminatory policies have been used to undermine its position. The world's most developed economies are not able to find ways to deal with the rise of China. China's global approach is raising serious concerns among major economies' leaders that do not seem to be able to come to terms with the idea that China will soon be the world's most powerful economy, and that the global status quo is being challenged. Further research should consider the implications of policy uncertainty in global and regional economies and the implications for investment decisions, firm-level investment decisions, unemployment, sectoral performance, and policies that seek to minimize the effect of external shocks in the context of the GCR.

Author Contributions: Both authors contributed to all aspects of the research.

Conflicts of Interest: The authors declare no conflict of interest. 


\section{Appendix}
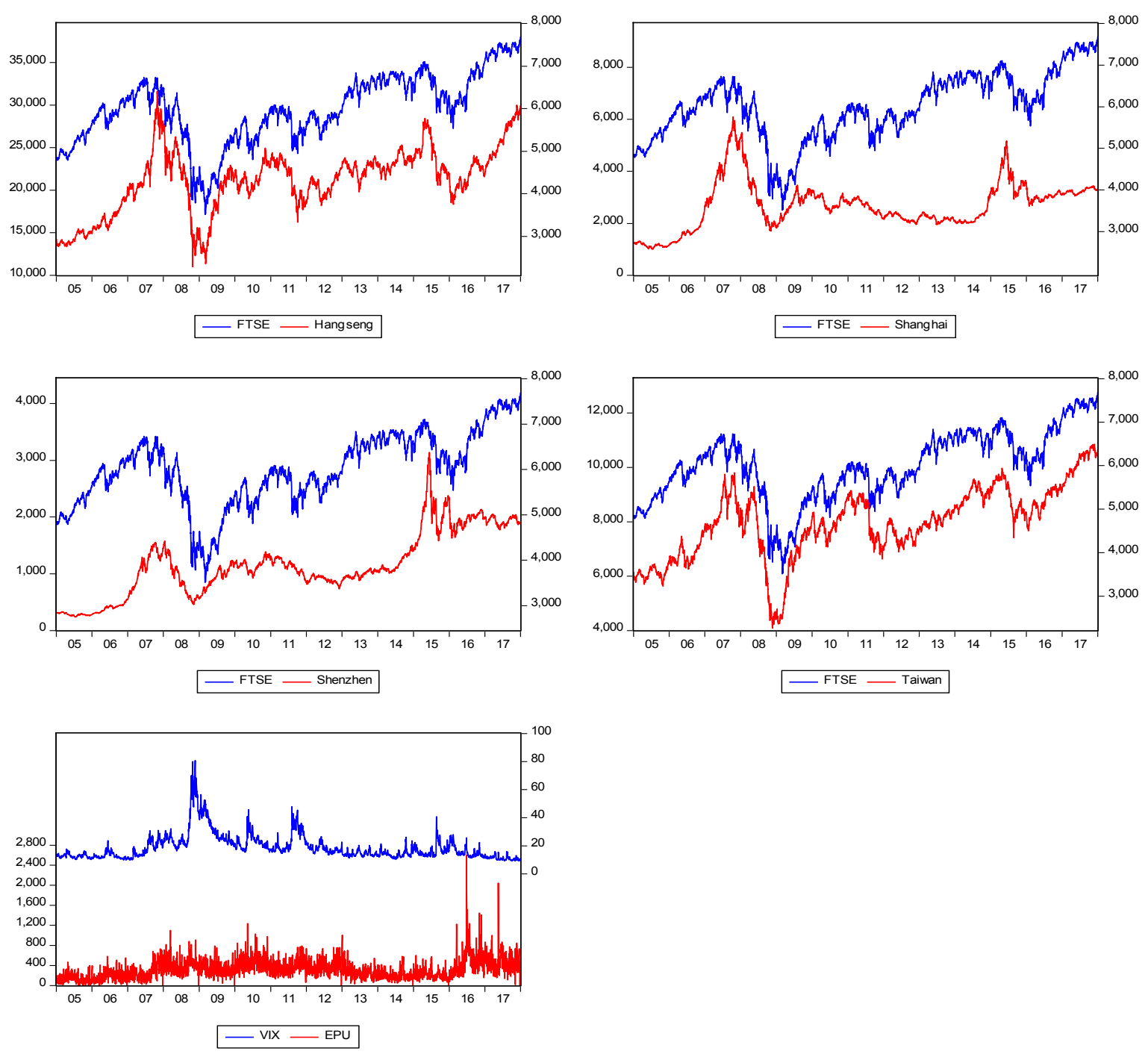

Figure A1. Indices Behavior from 2005 to 2017. 

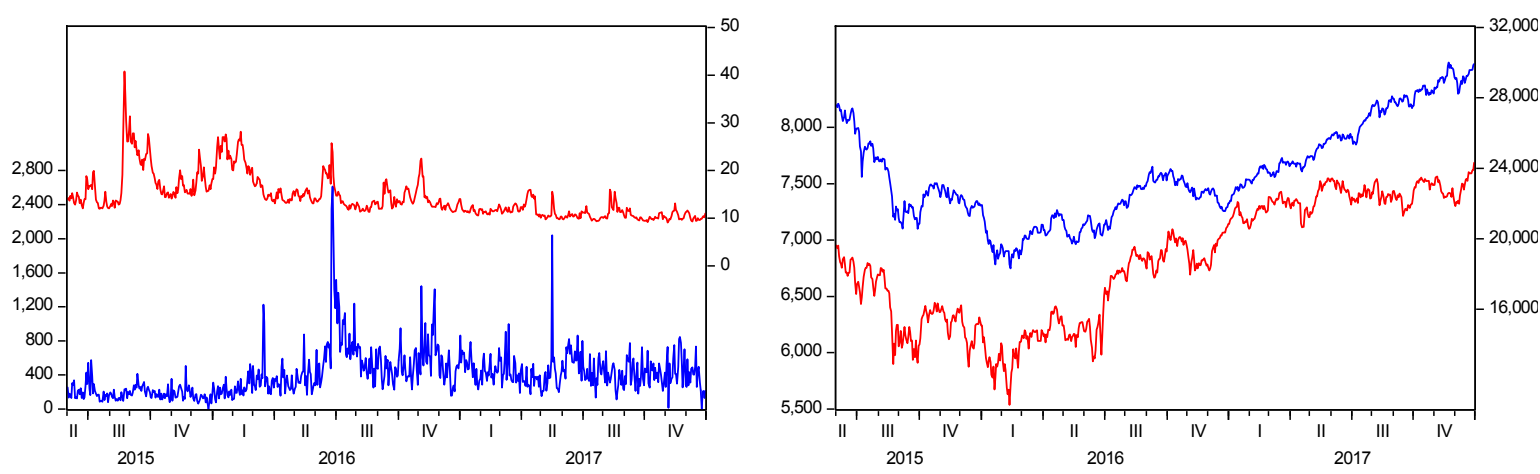

$-\mathrm{EPU}-\mathrm{VIX}$
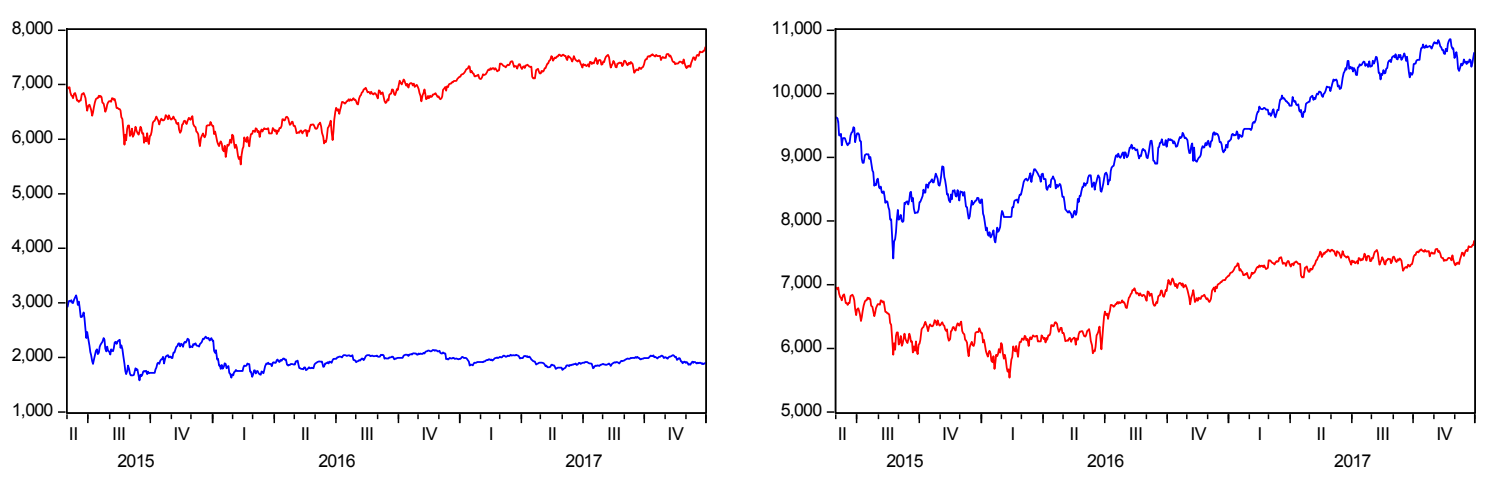

- Shenzhen — FTSE

- Taiwan — FTSE

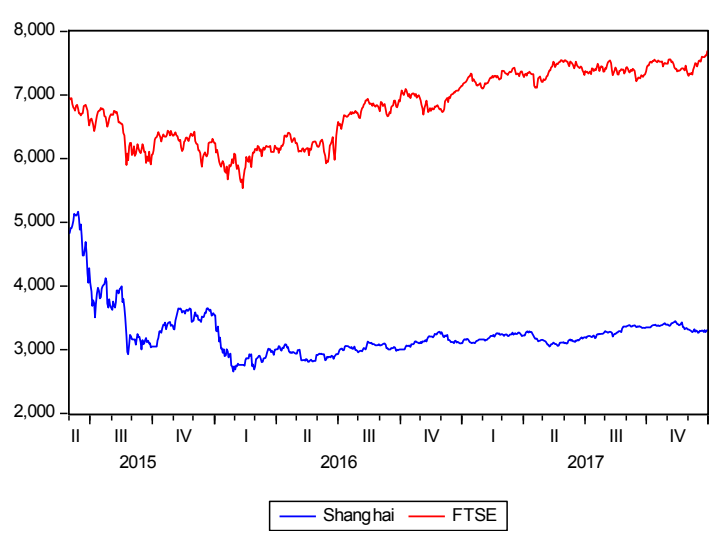

Figure A2. Pairwise Indices-Subsample Post Brexit. 
FTSEVOL

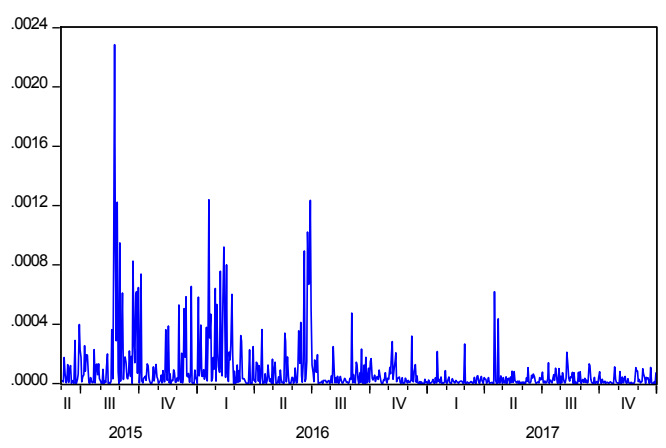

SHANGHAIVOL

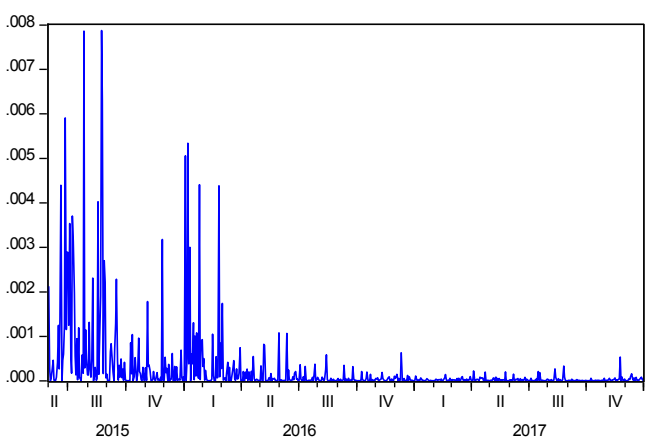

TAIWANVOL

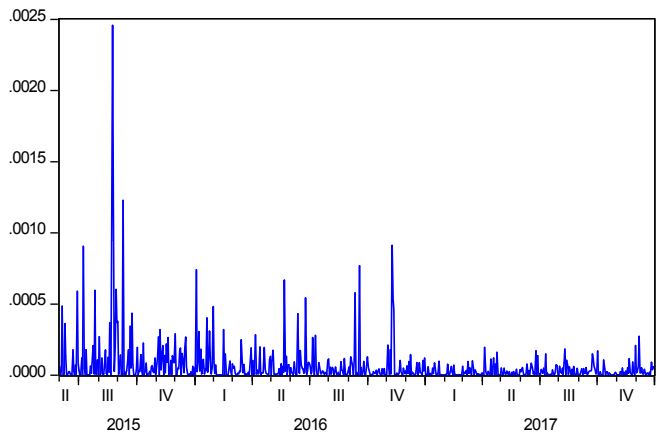

HANGSENGVOL

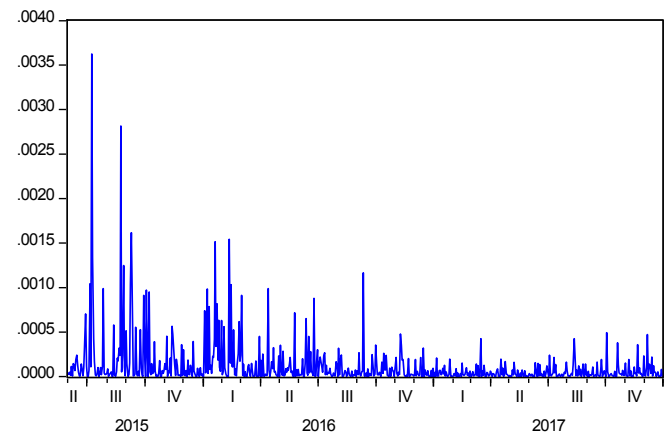

SHENZHENVOL

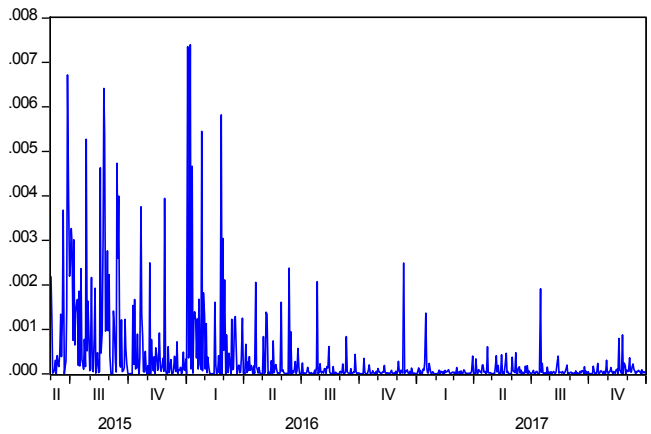

Figure A3. Historical Volatility—post Brexit.

Table A1. Residual Tests: OLS estimation.

\begin{tabular}{ccccccc}
\hline \multirow{2}{*}{$\begin{array}{c}\text { Residuals } \\
\text { Tests }\end{array}$} & \multicolumn{2}{c}{ Model 01 } & \multicolumn{2}{c}{ Model 02 } & \multicolumn{2}{c}{ Model 03 } \\
\cline { 2 - 7 } & $\begin{array}{c}\text { Serial } \\
\text { Correlation }\end{array}$ & Heterokedasticity & $\begin{array}{c}\text { Serial } \\
\text { Correlation }\end{array}$ & Heterokedasticity & $\begin{array}{c}\text { Serial } \\
\text { Correlation }\end{array}$ & Heterokedascticity \\
\hline Hang Seng & 1.857 & $16.57^{*}$ & 1.999 & $20.285^{*}$ & $14.680^{*}$ & 26.383 \\
& $(0.1568)$ & $(0.000)$ & $(0.1362)$ & $(0.000)$ & $(0.000)$ & $(0.000)$ \\
\hline \multirow{2}{*}{ Shanghai } & 2.712 & 48.65 & 2.272 & $50.034^{*}$ & $7.417^{*}$ & 41.296 \\
& $(0.0671)^{* * *}$ & $(0.000)$ & $(0.1039)$ & $(0.000)$ & $(0.000)$ & $(0.000)$ \\
\hline \multirow{2}{*}{ Shenzhen } & 1.644 & 37.274 & 0.8068 & $37.2635^{*}$ & $6.7633^{*}$ & $27.618^{*}$ \\
& $(0.1945)$ & $(0.000)^{*}$ & $(0.4467)$ & $(0.000)$ & $(0.001)$ & $(0.000)$ \\
\hline \multirow{2}{*}{ Taiwan } & 1.542 & $82.399^{*}$ & 0.9262 & $80.1406^{*}$ & $12.4208^{*}$ & $18.7637^{*}$ \\
& $(0.2145)$ & $(0.000)$ & $(0.3966)$ & $(0.000)$ & $(0.000)$ & $(0.000)$ \\
\hline
\end{tabular}

Levels of significance: * 1 percent and ${ }^{* * *} 10$ percent. The OLS estimation is corrected by the Newey-West covariance coefficient variance. 


\section{References}

Antonakakis, Nikolaos, Ioannis Chatziantoniou, and George Filis. 2013. Dynamic co-movements between stock market returns and policy uncertainty. Economics Letters 120: 87-92. [CrossRef]

Arouri, Mohamed, Christophe Estay, Christophe Rault, and David Roubaud. 2016. Economic policy uncertainty and stock markets: Long-run evidence from the US. Finance Research Letters 18: 136-41. [CrossRef]

Baker, Scott R., Nicholas Bloom, and Steven J. Davis. 2014. Measuring Economic Policy Uncertainty. Unpublished Working paper, Stanford University, Stanford, CA, USA; University of Chicago, Chicago, IL, USA.

Baker, Scott R., Nicholas Bloom, and Steven J. Davis. 2016. Measuring economic Policy uncertainty. The Quarterly Journal of Economics 131: 1593-636. [CrossRef]

Baker, Scott, Nicholas Bloom, and Steven J. Davis. 2012. Measuring Economic Policy Uncertainty. Working Paper Series, Stanford University, Stanford, CA, USA.

Benáček, Vladimir, Helena Lenihan, Bernadette Andreosso-O'Callaghan, Eva Michalíkovác, and Denis Kan. 2014. Political Risk, Institutions and Foreign Direct Investment: How Do They Relate in Various European Countries? The World Economy 37: 625-53. [CrossRef]

Bin, Feng-Shun, Lloyd P. Blenman, and Dar-Hsin Chen. 2004. Valuation impact of currency crises: Evidence from the ADR market. International Review of Financial Analysis 13: 411-32. [CrossRef]

Brewer, Thomas L. 1981. Political Risk Assessment for Foreign Direct Investment Decisions: Better Methods for Better Results. Columbia Journal of World Business 16: 5-12.

Brogaard, Jonathan, and Andrew Detzel. 2014. The Asset Pricing Implications of Government Economic Policy Uncertainty. Management Science 61: 3-18. [CrossRef]

Chang, Tsangyao, Wen-Yin Chen, Rangan Gupta, and Duc Khuong Nguyen. 2015. Are stock prices related to political uncertainty index in OECD countries? Evidence from bootstrap panel causality test. Economic Systems 39: 288-300. [CrossRef]

Cheng, Hwahsin, and John L. Glascock. 2005. Dynamic Linkages between the Greater China Economic Area Stock Markets-Mainland China, Hong Kong, and Taiwan. Review of Quantitative Finance and Accounting 24: 343-57. [CrossRef]

Chen, Xiurong, Yixiang Tian, and Rubo Zhao. 2017. Study of the cross-market effects of Brexit based on the improved symbolic transfer entropy GARCH model-An empirical analysis of stock-bond correlations. PLoS ONE 12: e0183194. [CrossRef] [PubMed]

Clark, Ephraim. 1997. Valuing Political Risk. Journal of International Money and Finance 16: 477-90. [CrossRef]

Clark, Ephraim, and Radu Tunaru. 2003. Quantification of Political Risk with Multiple Dependent Sources. Journal of Economics and Finance 27: 125-35. [CrossRef]

European Parliament. 2016. China's Proposed Market Economy Status: Defend EU Industry and Jobs. Available online: http:/ / www.europarl.europa.eu/news/en/news-room/20160504IPR25859/china\%E2\%80\%99sproposed-market-economy-status-defend-eu-industryand-jobs-urge-meps (accessed on 11 December 2017).

Fernández-Villaverde, Jesús, Pablo Guerrón-Quintana, Keith Kuester, and Juan Rubio-Ramírez. 2014. Fiscal Volatility Shocks and Economic Activity. American Economic Review 105: 3352-84. [CrossRef]

Goodell, John W., and Sami Vähämaa. 2013. US presidential elections and implied volatility: The role of political uncertainty. Journal of Banking and Finance 37: 1108-17. [CrossRef]

Guidi, Francesco, Christos S. Savva, and Mehmet Ugur. 2016. Dynamic co-movements and diversification benefits: The case of the Greater China region, the UK and the US equity markets. Journal of Multinational Financial Management 35: 59-78. [CrossRef]

Gulen, Huseyin, and Mihai Ion. 2013. Policy Uncertainty and Corporate Investment. Working paper, Purdue University, West Lafayette, IN, USA.

Henderson, Jane, and Eva Pils. 2016. Brexit and International Relations. The impact of Brexit on Relations with Russia and China. King's Law Journal 27: 473-88. [CrossRef]

Ho, Kin-Yip, and Zhaoyong Zhang. 2012. Dynamic Linkages among Financial Markets in the Greater China Region: A Multivariate Asymmetric Approach. The World Economy 35: 500-23. [CrossRef]

Hufbauer, Gary Clyde, and Cathleen Cimino-Isaacs. 2016. The Outlook for Market Economy Status for China. Washington: Petersen Institute for International Economics, Available online: https:/ / piie.com/blogs/tradeinvestment-policy-watch/outlook-market-economystatus-china (accessed on 5 November 2017). 
Kang, Wensheng, and Ronald A. Ratti. 2013. Oil shocks, policy uncertainty and stock market return. Journal of International Financial Markets, Institutions and Money 26: 305-18. [CrossRef]

Kang, Wensheng, and Ronald A. Ratti. 2015. Policy uncertainty in China, oil shocks and stock returns. Economic Transition 23: 657-76. [CrossRef]

Le Corre, Philippe, and Jonathan Pollack. 2017. China's Rise: What about a transatlantic dialog? Asia Europe Journal 15: 147-60. [CrossRef]

Lean, Hooi Hooi, and Duc Khuong Nguyen. 2014. Policy Uncertainty and performance characteristics of sustainable investments across regions around the global financial crisis. Applied Financial Economics 24: 1367-73. [CrossRef]

Leinen, Jo. 2016. Red lines for Brexit negotiations with the UK. In Fabian Policy Report: Facing the Unknown. Edited by O. Bailey. London: Fabian Society, p. 27.

Li, Xiao-Ming, and Lu Peng. 2017. US economic policy uncertainty and co-movements between Chinese and US stock markets. Economic Modelling 61: 27-39. [CrossRef]

Liu, Li, and Tao Zhang. 2015. Economic policy uncertainty and stock market volatility. Finance. Research Letters 15: 99-105. [CrossRef]

Luo, Chih-Mei. 2017. Brexit and its Implications for European Integration. European Review 25: 519-31. [CrossRef]

Mahbubani, Kishore. 2017. It's a Problem that America is still unable to Admit it will Become \#2 to China. New Perspectives Quaterly 34: 34-39.

Manzoor, Hasnain. 2013. Impact of pak-US relationship news on KSE-100 Index. Basic Research Journal of Business Management and Accounts 2: 1-24.

Palamalai, Srinivasan, Mariappan Kalaiwani, and Christopher Devakumar. 2013. Stock Market Linkages in Emerging Asia-Pacific Markets. Sage Open 3: 1-15. [CrossRef]

Pan, Rui. 2015. China's WTO Membership and the Non-Market Economy Status: Discrimination and impediment to China's foreign trade. Journal of Contemporary China 24: 742-57. [CrossRef]

Pastor, Lubos, and Pietro Veronesi. 2012. Uncertainty about Government Policy and Stock Prices. The Journal of Finance 67: 1219-64.

Pastor, Lubos, and Pietro Veronesi. 2013. Political uncertainty and risk premia. Journal of Financial Economics 110: 520-45.

People's Daily. 2016. China's Economy Likely to Follow “L-Shaped” Path in Coming Years, Says an "Authoritative Insider". People's Daily. May 9. Available online: http:/ / en.people.cn/n3/2016/0509/ c98649-9055137.html (accessed on 11 January 2018).

Reboredo, Juan C., and Gazi Salah Uddin. 2016. Do financial stress and policy uncertainty have an impact on the energy and metals markets? A quantile regression approach. International Review of Economics and Finance 43: 284-98. [CrossRef]

Root, Franklin. 1973. Analysing Political Risks in International Business. In Multinational Enterprise in Transition. Edited by Kapoor Ashok and Phillip D. Grub. Hoboken: Wiley Online Library.

Simon, Jeffrey D. 1982. Political Risk Assessment: Past Trends and Future Prospects. Columbia Journal of World Business 17: 62-70.

Yu, Jie. 2017. After Brexit: Risks and Opportunities to EU-China Relations. Global Policy 8: 109-14. [CrossRef]

Yu, Jie. 2016a. China is an Unexpected Strong Supporter of the Remain Camp, LSE Blog. Available online: http://blogs.lse.ac.uk/brexit/2016/06/15/china-is-an-unexpectedly-strong-supporter-of-theremaincamp/ (accessed on 13 December 2017).

Yu, Jie. 2016b. China's Brexit Dilemma, Heinrich Boell Stiftung Dossier. Available online: https:/ /www.boell.de/ en/2016/07/28/chinasbrexit-dilemma (accessed on 21 November 2017).

Wang, Shucheng. 2017. Brexit's Challenge to Globalization and Implications for Asia: A Chinese Perspective. Journal of East Asia and International Law 10: 47-64. [CrossRef]

Wang, Yizhong, Carl R. Chen, and Ying Sophie Huang. 2014. Economic policy uncertainty and corporate investment: Evidence from China. Pacific-Basin Finance Journal 26: 227-43. [CrossRef]

(C) 2018 by the authors. Licensee MDPI, Basel, Switzerland. This article is an open access article distributed under the terms and conditions of the Creative Commons Attribution (CC BY) license (http:/ / creativecommons.org/licenses/by/4.0/). 